\title{
Impact Of IT Factors In Nepali Small Family Business Turnover
}

\author{
Bijay Kumar Kandel
}

PhD, Visiting Professor, University of South Pacific, Suva, Fiji, Universidad Tecnologica de La Laguna Durango, Mexico

\section{Jyotirmayee Acharya}

PhD, Associate Professor, Sri Sri University, Odisha, India

\begin{abstract}
This paper summarizes the arguments and counter arguments within the scientific discussion on the issue of IT adoption and its turnover impact on Small family Businesses. The main purpose of the research is to determine and analyze the information technology (IT) factors that impact different annual turnover outcome of small family businesses (SFBs) in Nepal.

There are many literary sources found in relationship between technology adoption from developed countries. Also, there are literary sources and approaches from developing countries. But the scientific problem is that literature on adoption studies lack to suggest IT adoption positively affects SFBs' annual turnover performance. Therefore, investigation of the topic Impact of IT factors in Nepali small family business turnover in the paper is carried out in the following logical sequence: introduction, literature review and hypothesis development, methodology, logit model analysis and finally conclusion. Methodological tools of the research methods were two and half years of research. The total population of the research covered SFBs owners/managers only from selected four districts of Lumbini zone, Nepal. The paper presents the results of an empirical analysis using binominal logistic regression model. This research uses the results from a survey of 210 SFBs owner/manager. Instrument reliability was measured by Cronbach's alpha. The research result empirically confirms and theoretically proves that SFBs having good infrastructures in the form of Internet, telephone and people are more likely to positively influence performance and have positive impact on annual turnover. It was also found that estimated probability that the turnover of SFBs increases with respect to age. The results of the research can be useful for government policy makers, researchers and small family business owner/managers.
\end{abstract}

Keywords: IT adoption, performance, small family business, turnover, Lumbini zone, Nepal.

JEL Classification: M15, O32.

Cite as: Kandel, B.K., Acharya, J. (2018). Impact Of It Factors In Nepali Small Family Business Turnover. SocioEconomic Challenges, 4(2), 87-100. https://doi.org/10.21272/sec.4(2).87-100.2018.

(C) The Authors, 2018. This article is published with open access at Sumy State University.

\section{Introduction}

IN the past, small family businesses (SFBs) have lagged behind large firms in adoption of information technology (IT). However in the last two decades small family businesses (SFBs) have invested heavily in information and technologies (IT). The reason may be the rapid economic and technological development in the global business makes the strategic use of IT essential. According to Knol and Stroeken (2001), small businesses are running behind the application of IT and therefore it is necessary to stimulate the diffusion and adoption of this technology within this group. Some studies suggest that the IT has allowed small businesses to compete effectively and efficiently in both domestic and international markets (Thong, Yap, and Raman 1996). Further, Thong and Yap (1996) suggests that with the decreasing cost and ever more powerful userfriendly micro-computers and standard software packages, today the benefits are accessible even to the smallest businesses.

On the other hand the benefit of the use of Information Technology (IT) and firm performance has widely researched (Alpar and Kim, 1990; Harris and Katz, 1991; Rai, et al., 1997; Newman and Kozar, 1994; Mukhopadhyay et al., 1995). However, specific to small family businesses (SFBs) is yet to be researched. Therefore, this study seeks to identify and analyze the factors that impact different annual turnover outcome of SFBs in the Lumbini zone of Nepal. 


\section{Literature review}

A literature review conducted by Lesjak (1998), revealed that IT has been described as facilitating organizational transformation, increasing market share, and heightening customer services because it provides information and communication channels among various participants in a way that has altered the basis for industry competition. There are many reported cases in literature of positive contribution of IT to SFBs in developed countries.

According to Ogbonna and Harris (2005), in an international context, IT has been long recognized by modern organizations as an important operational and strategic business tool for: improving productivity, quality, and effectiveness, creating or maintaining competitive advantage, and redesigning business processes to better support company strategy. Referring Abouzeedan and Busler (2006), to the potential benefits that business can obtain when it utilizes IT are extensive and include efficiency gains (e.g. the automation of clerical procedures), increased management effectiveness (e.g., in decision-making) and improved business performance (e.g., by entering into strategic alliances with other firms). Further, author suggests that the falling costs of computer software, hardware and telecommunications and associated performance improvements have and can enable SFBs to re-examine the way that they conduct business and come up with more cost effective practices.

Other scholars have noted that SFBs can minimize their usual size disadvantage over many competitor organizations (Ogbonna and Harris, 2005), geographical borders and new business start-ups can enjoy particularly in closing the gap between them and their more established competitors (Oviatt et al., 1995), superior performance and competitive advantage over local and international rivals (Hymer, 1976; Dosi, 1982), international activities (Gallo and Pont, 1996; Davis and Harveston, 2000) reduce operational problems, increase profit, improve client attendance, improve service and products, decrease stock and personnel reduction, (Zwicker et al., 2006) are some examples.

However, while the developed countries SFBs forged ahead with more advance IT use, developing countries struggled to keep pace with emerging technologies (Kandel, 2012). According to Baard (2003), the developing countries SFBs owner/managers fail to adopt IT as effectively for various reasons: first, they are unable to analyze processes or systems that make a business work; second, a lack of general knowledge of IT; third, a lack of expertise to computerize the SFB; fourth, a limited access to and ownership of financial resources; fifth, a reliance on outside sources to assist in the SFBs computerization process and lack of a formal, affordable means to assist in the decision-making process as to what IT to use where, when and how within the SFB environment. Also, it is generally assumed that SFBs in developing countries have poor human and financial resources (Caldeira and Ward, 2003; Kandel, 2012) therefore SFBs in developing countries are less capable, less prepare and less able to change then SFBs in developed countries of accessing and using IT to gain its benefits.

These factors certainly applies to the adoption of IT in Nepalese SFBs as well; as Nepalese SFBs have such an important position in the national economy and the level of application of IT in SFBs is relatively lower than in international counterparts. Growing number of Nepalese SFBs are under pressure from their international counterparts to change their traditional management style, both operationally and organizationally, replacing with integrated system that can help them to increase the speed and fluidity of physical and information flows. In order to reach this kind of integration Nepalese SFBs are investing on IT.

Identifying IT factors of SFBs is fundamental for ensuring a successful adoption process (Bruque and Moyano, 2007). Researcher has identified variables that can explain why SFBs adopt IT with different intensities and speeds in developing countries (Baard, 2003; Zwicker et al., 2006). According to Kapurubandara and Lawson (2007), there are special variables based on the socio-economic as well as the wider socio-political context, such as sustainability, afford ability, socio-economic justification and community should be taken into consideration in developing countries like Nepal. However, to date there is no research in terms of identifying IT factors influencing SFBs performance. 


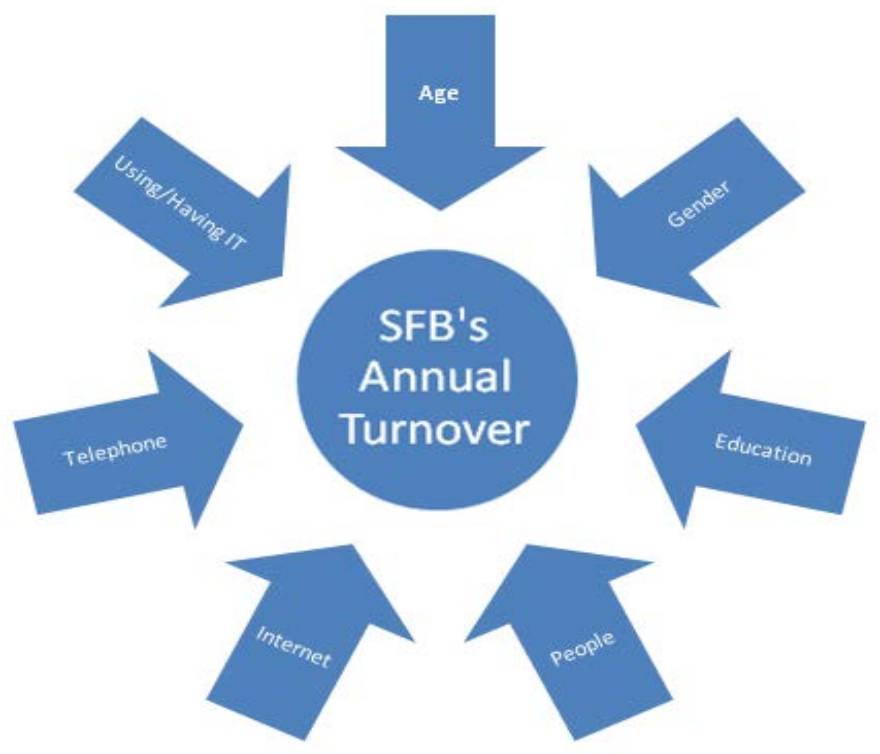

Figure 1. Socio-economic factors

Therefore, the main aim of this study is to identify and analyze the IT users performance in small family businesses (SFBs) in districts in Lumbini Zone of Nepal (see Figure 2). Also, identity the factors those are huddle for SFBs in terms of adopting IT and removing the gap between SFBs and government which is believed to be the principal cause of government failure in the management of SFBs and build a social awareness in order to help SFBs by increasing their annual turnover. In following sections we briefly discuss factors those are listed in literatures and develop hypothesis for this study.

\section{A. Hypotheses development}

There are many studies found in relationship between technology adoption from developed countries (Harrison and Huntington 2001; Stedham\& Yamamura, 2004; Chouderia\& Lee 2004; Evens and Yen, 2005). Also, there are studies from developing countries (Kasckende, Oshikoya, ondoege and Dasah, 2006). Extant literature on adoption studies have not considered lack to suggests that IT adoption positively affects SFBs' annual turnover performance. Therefore, here for this study we developed seven hypotheses to determine the factors that influence SFBs' annual turnover. Seven interrelated variables were identified as annual turnover performance determinants and seven hypotheses were formulated. Our aim here is to test the hypothesis and determine the strength of the relationships. In the literature, the prior research on medium small enterprises (SMEs) has focused on developed countries and small business comparatively little work has been done to see how the SFBs IT adoption in developing countries and their annual turnover performance.

\section{Having/using IT}

The first factor considered for hypothesis is having/using technology. SFB's those have adopted IT previously or already using are more likely to have interest to posses more IT in future (Thong, 2001; Thong \& Yap, 1995). Study by Caldeira and Ward (2003) found that the positive result in relative success of IT in manufacturing industry. On the other hand literature provided evidence that higher level of success and satisfaction with IT adoption and use in SMEs (Premkumar, 2003; Thong, 2001; Fink, 1998; Ghobakhloo et al., 2011). In the US economy during 1986 to 1991, the rapid use of IT during this period, overall growth in productivity slowed due to the largest investment in IT (Landauer, 1995). The literature in particular to SMEs suggests that IT use is another trait affecting IT adoption (Drew, 2003; Lybaert, 1998; Ghobakhloo et al., 2001; Chuang et al., 2015). In particular, Premkumar and Roberts (2003) suggests that user's awareness of the benefits of IT will also positively influence the process of adopting IT.

H1. In an attempt to understand this puzzle; we hypothesize that there is a positive relationship between having/using IT and SFB annual turnover performance. 


\section{Infrastructure}

Early studies suggests that small businesses lack infrastructure (Berry and Wood, 1998; Bajwa et al., 2005; Adhikari and Pradhan, 2002; Tan and Macaulay, 2007; Thapa and Paudel, 2006; Bhattarai and Gupta, 2008; Gautam, 2012; McCauley et al., 2006). Particularly; Andersen et al. (2005) model for analyzing environmental factors focuses on drivers such as” telecommunication, internet infrastructure and wireless.

\section{a) Telephone infrastructure}

Based on Bruque and Moyano (2007); and Bajwa et al. (2005), the telephone infrastructure should be considered as one influence factor for IT adoption. The poor telephone infrastructure is considered in developing countries as a barrier factor as a stumbling block to the necessary IT adoption. Another problem is the very low quality and reliability of the public telephone network Salampasis (2001). In the literature about telephone (Hardy 1980); Hardy's supports the idea that the greater availability of telephones has a positive effect on financial outcome of business and the GDP of the country. Also, Norton (1992); paper investigates the effects of telephone infrastructure on growth rates of income.

H2. In this study we hypothesize that there is a positive relationship between telephone infrastructure and SFB annual turnover performance.

\section{b) Internet infrastructure}

The third factors considered for this study is internet infrastructure. In SMEs; researchers talk about lack of access to internet (Mukti 2000; Kraemer, Gibbs, and Dedrick 2005; Ochara, Van Belle, and Brown 2008; Brown and Thompson 2011) as IT adoption barrier. Additionally, it should be pointed out the absence of any Internet Service Provider (ISP) and the lack of any kind of widely used data network can be barriers for IT adoption in small businesses in developing countries.

H3. Here we hypothesize that there is a positive relationship between Internet infrastructure and SFB annual turnover performance

\section{Gender}

Article by Gillard, Howcroft, Miter \& Richardson (2008); suggests gender does not only refers to the biological traits (i.e. men or/and women) but, rather it explains the notion of feminist and masculinity. Studies by Heilbrun, (1976) and Hofstede, (1991) have acknowledged that gender can determine human behaviour and management decision-making processes. Indeed, gender can have an influential role in determining how owner/manager respond to and use technology (Gefen and Straub 1997). Authors Jimmie and Somnath (2010) in examining the relationship between gender and IT adoption found that females had fewer computers at home compared to men. Gefen and Straub (1997) in extending Davis' technology acceptance model to investigate perceptual differences and use of E-mail, found that men and women differ in their perceptions of E-mail. This was linked to the tendency of men to feel more comfortable using technology than women. Furthermore, in technology-driven markets, often early adopters of new technological innovations are primarily young male executives (Lu, Plataniotis, and Venetsanopoulos 2003). One possible reason is that females are less inclined and motivated to adopt and use technology than males (Qureshi and Hoppel 1995). SME and small business literature suggest that the gender of the owner/manager may influence the IT adoption (Culkin and Smith 2000; MacGregor and Vrazalic 2007; Martin and Halstead 2003). Literature suggests that women are usually slow in adopting IT, than males (Cao and Mokhtarian 2005; Chang, Cheung, and Lai 2005). According to Macgregor and Vrazalic (2007); male owner/managers may be more open to IT adoption since they are more willing to use IT.

H4. Hence, we hypotheses that there is a positive relationship between gender and SFB annual turnover performance

\section{Age}

The age of the owner/manager can affect the way decision are made within the business (Culkin and Smith 2000; Palvia and Palvia 1999; Baakeel and Alrashidi 2012). Older owner/managers can be less attractive towards IT as they are more conservative and have less willingness to take risk than the young owner\managers. Also, old owner/managers may also lack the necessary knowledge or/and skills to manage IT since they have not grown up with this technology (Brock 2000; Palvia and Palvia 1999). 
The study by Al-Ghantani et al (2007) indicates that age is a significant negative correlation with the acceptance of IT. On the other hand, some researchers argue that young owner/managers are more open to change (Huber, Herrmann, and Morgan 2001), therefore they do not hesitate to try available technology.

A number of studies (Hambrick and Mason 1984; Czaja and Sharit 1998; Venkatesh and Davis 2000; Dwivedi et al. 2009) have found that the age of the managers can significantly influence the extent of IT adoption within SMEs. IT adoption, for example, may be more profound in business managed by younger executives than those managed by older ones. Child (1974) in studying the managerial factors influencing company performance illustrated that younger executives are more driven by risk-taking, innovation and achievement compared to their senior counterparts. This may be explained by the apparent conservative stance of older executives (Chown 1960; Child 1974) or older executives avoiding any risky action capable of disrupting their social norms or infringing on his or her retirement benefits (Carlsson and Karlsson 1970).

H5. This leads us to hypothesis that there is a positive relationship between age and SFB annual turnover performance

\section{Education}

A number of studies (Bruque and Moyano 2007; Chuang, Nakatani, and Chen 2015) suggests that education level of owners/managers have can influence the IT adoption. Akkeren and Harker (2003), for example, found that the computer literacy of the business owner can also influence technology adoption. According to Kirby and Turner (1993); Thong et al. (1996) if the owners don't have basic literacy; they are unaware or do not understand the technologies available, they are unlikely to adopt them into their own businesses. Highly educated manager/owner has a greater tendency to learn technology and diffuse its benefits to the rest of the organizational workforce (Bruque and Moyano 2007). Education is thought to improve the SFBs ability to better process the information provided about new technologies and to increase their locative and technical efficiency (Jamison, Lau, and others 1982). Furthermore, literature also suggests owner/manager with weak education often exhibit high levels of risk aversion because they feel threatened by change and only invest after first-mover advantages have been lost to other executives who, perhaps, have better education backgrounds. Rogers (1995) recognized that highly innovative owner/manager aggressively thrives.

H6. We hypothesize that there is a positive relationship between education of SFB owner/manager and SFB annual turnover performance.

\section{People}

According to Thong and Yap (1995), small business suffers from a special condition commonly referred to as resource poverty. Businesses that have more employees tend to adopt IT (Thong and Yap 1995; Hartono 2012; Link and Bozeman 1991). Adapting IT in business can depend on attitudes of the working people in business, their qualifications and, people performance and the extent of their knowledge of information technology. Teo and Tan (1998) suggest that the main reasons for not adopting the IT is lack of internal expertise of the working people. Lack of expertise can delay adoption process (Thong 1999). If people in business already have some knowledge of information technology, in that case the business may be more disposed to adopt IT (Huy and Filiatrault 2006; Looi 2005; Molla and Licker 2005). Laforet Tann, (2006); Thong (1999); mention that larger businesses have more resources and infrastructure to facilitate IT adoption, and small business suffer from lack of people (Thong and Yap 1995) and IT expertise (Welsh and White 1981). Locke (2004) study in terms of turnover of employees found that there were no significant difference in ICT investment relating to turnover and number of people working in a business. Number of people working can be indicator for future success (Attewell 1992).

H7. We hypothesize that there is a positive relationship between people in SFB and SFB annual turnover performance

It is hypothesized that the all seven constructs are all related positively to the SFBs annual turnover performance. Furthermore, it is hypothesized that the seven constructs are all related positively. The next section will discuss the methodology that is being used to conduct this investigation. 


\section{Methodology}

\section{A. Quantitative Research Method}

The choice between the qualitative and quantitative research methods has been discussed by a number of authors (Hausman 2005; Hasnu and Amjad 2007; Levenburg 2005). Here, to fully understand the forces affecting IT adoption and impact on performance of Nepalese SFBs, the quantitative method is used to describe the demographic characteristics of the owners/managers and SFBs, explore the level of interest of the SFBs, and to identify the factors determining the IT adoption and impact on their annual performance. The quantitative method uses the numerical data sampled from a large population and aims to generalize the findings to the population. The representativeness of the sample to the population, sampling methods, the operation of the variables, measurement of the constructs, the pretext of the instruments, the reliability of the constructs or scales, the kinds of the instruments of data collection, and the techniques of data management and analysis are very important in the quantitative methods to draw valid conclusions from the study. These are briefly described below.

\section{B. Survey research approach}

Survey research approach was found to be suitable for identifying the frequency of certain characteristics amongst population or groups. It allows a researcher to relate various characteristics to explain a phenomenon. The aim is often to generalize the data to the whole group but this can be very difficult to prove with confidence. Recent studies conducted by Mingers (2001); Choudrie and Dwivedi (2005); suggests that case study and survey are presently dominant research methods used by researchers investigating technology adoption. According to Choudrie and Dwivedi (2005); about 74\% of the researches employed the survey approach and $26 \%$ of the research employed the case study methods and no other methods were employed to investigate use or adoption of technology.

\section{1) Population, Sample Size, and Sampling Frame}

As the study aims to identify the factors determining the IT adoption of the SFBs, the total population of the study covered SFBs owner/manager only from selected districts of Lumbini zone, Nepal.

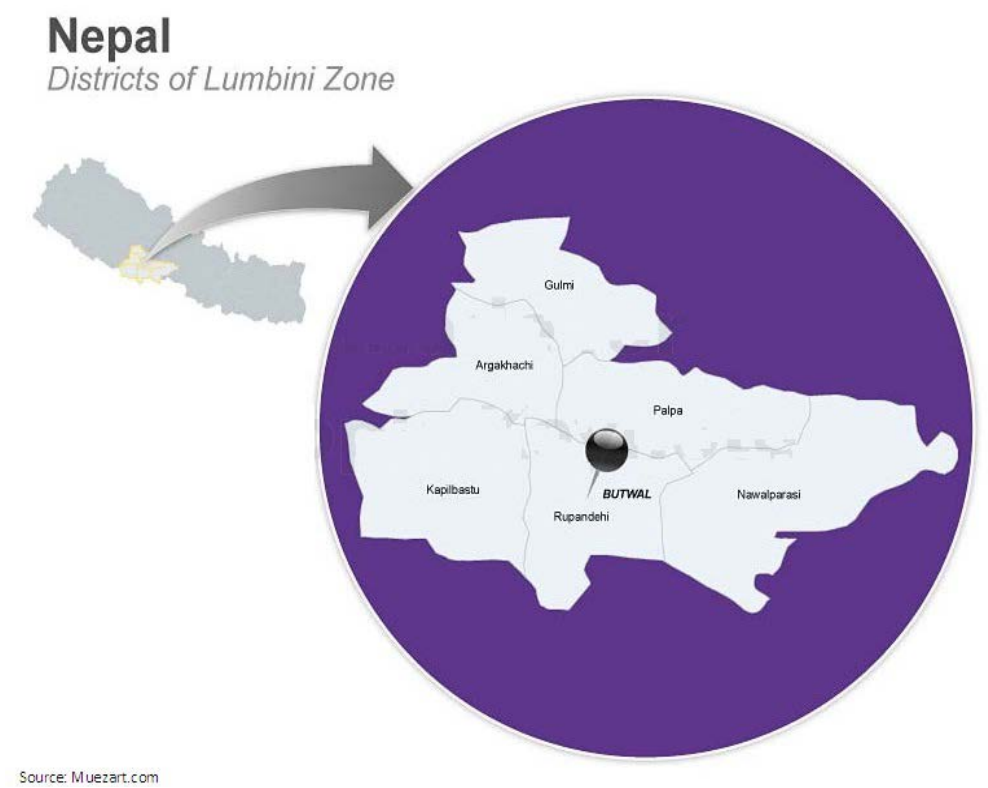

Figure 2. Districts of Lumbini

Review of statistics from Nepal government Centre of Bureau of Statistics (CBS) old figures from 2001 was found reporting total 12,228 SFBs operating in Palpa and Gulmi district. However, country wide study conducted by Sharma (2012) suggests that up to 1990/91 total registered cottage industries under Department of Cottage and Small Industries were 47,426 which reached 216,663 in 2009/10 of which only 60.3 percent of small enterprises were found to be registered. They estimate that about 600,000 micro enterprises are operating in rural and urban area both registered and unregistered. 
However, author also suggests that most of the micro-enterprises established so far are either agro-based, forest-based, or livestock-based and rest of them are metal based, weaving, and restaurant. All these mentioned categories are excluded in this research. Therefore, after excluding $65 \%$ this research estimated population is 34,153 SFBs in Gulmi, Palpa, Rupandhai and Kapilvastu; Nepal.

\section{A. Sample Size}

The population of the study covered four districts owners only from Gulmi, Kapilvastu, Rupandhai and Palpa. Sample size indicates the generalization of the findings to the population of the study.

It also depends on the nature of the study. Different scholars have provided different methods of determining sample size. Some scholars emphasize representing the population, and others the method of the analysis and variables used in the study. For instance, Krejcie and Morgan (1970) provided a table that helps researchers to determine the appropriate sample size representing the population at a short glance. According to their table, if the total population of the study is 50,000, the required sample size is 381 and 382 for a population of 75,000.

On the other hand, Cooper, Schindler, et al. (2003) argued that if the calculated sample size exceeds five percent of the population, the sample might be reduced without sacrificing precision. Meanwhile, Roscoe (1975) emphasized the types of research methods to determine the sample size. Roscoe stated a rule of thumb for determining the sample size for multivariate research, including multiple regression analysis where the sample size should be preferably 10 times or larger than the number of variables in the study (Roscoe 1975; Krejcie and Morgan 1970; Cooper, Schindler, and others 2003) quoted in Pant (2009). Based on the criterion specified in Krejcie \& Morgan's (1970), the adequate sample size for this level is 380 participants. However, while this research aims to achieve the optimum number of 380 readable responses, a sample size of 200 or over will be considered sufficient according to Table [1], which was based on the summary of several hundred studies representing a very broad sample size (Aaker et al. 2004; Hallal 2010).

Table 1. Seymour Sudman recommended guidelines of the sample size

\begin{tabular}{|l|c|c|}
\hline \multicolumn{1}{|c|}{ Details } & \multicolumn{2}{c|}{ Institutions } \\
\hline Number of subgroup analyses & National & Regional or special \\
\hline None or few & $200-500$ & $50-200$ \\
\hline Average & $500-1000$ & $200-500$ \\
\hline Many & $1000+$ & $500+$ \\
\hline
\end{tabular}

Source: adopted from Aaker et al. (2004).

According to Hair (2010), factor analysis is an interdependence technique used to define the underlying structure among variables in the analysis, which are the building blocks of relationships. The authors recommend that the sample size should not be fewer than 50 but preferably 100 or larger. The suggested sample size (100 or larger) complies with Roscoe (1975) proposal that sample size larger than 30 and/or less than 500 are appropriate for most research projects (Sekaran 2000). Taking this into account, this study recognizes the possible limitations of the minimum sample sizes (insensitive) and very large sample sizes (overly sensitive) (Hair 2010) and, obtain more than the minimum recommended sample size i.e. two hundred ten (210).

\section{Sampling procedure}

This research used a rigorous simple random sampling procedure to collect data because randomization ensures that each member of the population has an equal chance of being selected (Creswell 2013; Iacovou, Benbasat, and Dexter 1995; Churchill and Iacobucci 2009). Randomization reduces sampling error to a minimum and improves the meaningfulness of gathered data (Bryman 2008). This research aim was to generalize the findings from employed sample to the population so a single-stage simple randomized sampling procedure was carried out to pursue this objective. Also, it was possible to access each unit of the population and sample the potential respondents directly (Creswell 2013).

\section{Research Instruments}

The study used mainly primary data collected using structured questionnaires. The questionnaires were administered to SFB Owners/managers. For ease of filling, the questions in the survey tool were mainly closed ended, but for the purposes of allowing respondents to provide data not captured in the questions, some open-ended questions were also included. 


\section{Data Collection}

This section describes the actual data collection stage and analysis process. It will discuss the participant selection in which participants were selected, invited and interviewed. The field study took place between end of July - September, 2015. Data collection methods for qualitative research usually consist of interview, observation, documents and audio visual materials (Creswell 2013).

The main purpose of this research is to be helpful to the SFBs by virtue of observing the system. Some of the observations and intervention are made in the formal and informal settings of meetings and interviews. The survey method was used to collect primary data for the study. This method was used because of the wide area or the research study covered in the universe. Primary data was collected through the use of interview schedule. The questions covered personal, socioeconomic, institutional and other relevant variables too.

\section{Questionnaire \& Scale}

The questionnaire covered questions about the factors identified in the preliminary empirical study, which influence the SFB's willingness to adopt IT. The main nine sections in this questionnaire were:

Section one: this part of the questionnaire was related to basic personal questions about the participant, such as the gender, marital status, age group and education were included.

Section two: this was the longest section overall. It contained the close ended questions about SFB /structural factors such as SFB type, location, establishment, employees, turnover, type of IT technology items used, reason for first IT factors/ measures, importance of IT, and rate of infrastructure available. Factors were assessed by one to four box provided, yes/no and five Likert-type items, most of which were adopted from previous similar studies in the research field.

Section three: this section contained the questions used for studying the need for technology factors/ measures, assessed by five Likert-type items.

Section four: this section contained the questions used for studying the contextual factors / measures, assessed by five Likert-type items.

Section five: this section contained the questions used for studying the acquiring knowledge of technology factors/ measures, assessed by five Likert-type items.

Section six: this section contained the questions used for studying the sharing knowledge of technology factors/ measures, assessed by five Likert-type items.

Section seven: this section contained the questions used for studying the evaluating knowledge of technology factors/ measures, assessed by five Likert-type items.

Section eight: this section contained the questions used for studying the trust in technology factors/ measures, assessed by five Likert-type items.

Section nine: the last section mainly focused on viewing the using knowledge of technology factors/ measures, assessed by five Likert-type items.

\section{Reliability of the study instrument}

A reliability test was conducted to check for internal bias of the survey responses. First, 119 respondent results were used on a for reliability test. The first section was excluded as it was about personal details of the respondent age, sex, education and marital status. For others sections (B, C, D, E, F, G, H) the Cronbach Alpha was observed. The Cronbach Alpha was observed to be 0.8143 for section B (number of items 10); 0.8521 for section C (number of items 10); 0.7557 for section D (number of items 10); .7435 for section E (number of items 6); 0.7390 for section $F$ (number of items 4); 0.7399 for section $G$ (number of items 6); 0.7825 for section $\mathrm{H}$ (number of items 4). Three qualitative questions were excluded in the test. Finally, .9022 for section I (number of items 5). According to Santos and Haubrich (1999) the Cronbach Alpha coefficient must be more than 0.73 to be reliable. Above presented results are above .7390 therefore the data was justified to be used for further analysis. 


\section{Logit model analysis}

\section{A. Bi-nominal logistic distribution}

Before the variables were analyzed, from some factors accompanying each variable were combined and averaged. Binary logit regression model was considered for analysis due to the nature of the study because the situation would have to occur or otherwise. The outcome was to be either 0 or 1 , where 1 indicates that the outcome of interest is present, and 0 indicates the outcome is absent.

\section{Dependent variable (Binary)}

Annual Turnover is the dependent variable. The dependent variable is binary and describes the SFBs annual turnover. It was measured with value of one (1) meant positive annual turnover performance while zero (0) indicated negative annual turnover performance.

\section{Independent variable for the study}

Following (Hosmer Jr, Lemeshow, and Sturdivant 1989) this model building starts with binominal logistic regressions for each independent variable. There are seven independent variables. They are: having/using technology, telephone infrastructure, internet infrastructure, gender, age, education level and working people (employees).

\section{B. Performance Testing}

Table 2. Turnover as performance indicator

\begin{tabular}{|l|c|c|c|c|}
\hline & B & S.E & Sig. & Exp(B) \\
\hline Having Technology & $.701^{* * *}$ & .390 & .073 & 2.016 \\
\hline Telephone & $.666^{* *}$ & .333 & .045 & 1.946 \\
\hline Internet & $.764^{* *}$ & .316 & .015 & 2.147 \\
\hline Gender & .310 & .407 & .447 & 1.363 \\
\hline Age & $.762^{* *}$ & .378 & .044 & 2.143 \\
\hline Education & -.018 & .591 & .976 & .982 \\
\hline People & $.536^{* * *}$ & .317 & .090 & 1.709 \\
\hline Constant & $-3.013^{*}$ & .761 & .000 & .049 \\
\hline Hosmer\&Lemeshow Test & Chi-square & df & Sig. & .554 \\
\hline 1 & 6.843 & 8 & & .049 \\
\hline
\end{tabular}

Source: own compilation.

Note: ${ }^{*}, * *$ and $* * *$ denotes level of significance at $1 \%, 5 \%$ and $10 \%$ respectively.

Most of the variables such as (having technology, telephone infrastructure, Internet infrastructure, gender, age, people) in the logistic regression model [Table: 2] are found to be positive and significant determinants in influencing the performance of SFBs. The estimated coefficient of using/having IT is 0.70 and its corresponding odds ratio is 2.016 .

The probability that the turnover of SFBs improves with respect to having technology is 67 percent. It means that SFBs adopting IT are more likely to positively influence turnover.

The SFBs having good infrastructures in the form of Internet, telephone and people are more likely to positively influence their performance. As shown above in the Table [2]; the estimated probability of turnover ratio with respect to telephone and Internet were 66 and 68 percent respectively. Also, for the people the probability that turnover ratio increases with respect to people is 63 percent. The coefficient of the personal factor mentioned in the model i.e. age was found to be .76 and its corresponding odds ratio is 2.143. The estimated probability that the turnover of SFBs can increase with respect to age is 68 percent.

\section{Hypothesis Testing}

The seven hypotheses that the study sought to test are addressed in this section.

The variables and their measurement can be summarized in Table [3] below. 
Table 3. Variables, Description, Estimated Hypothesis and Logit Test Result

\begin{tabular}{|l|c|c|c|}
\hline \multicolumn{1}{|c|}{ Variables } & Description & Predicted Sign & Logit Test Result \\
\hline Annual Turnover & SFBs Annual Turnover & Constant & Constant \\
\hline Telephone & Telephone infrastructure & + & + \\
\hline Internet & Internet infrastructure & + & + \\
\hline Gender & SFBs participants gender & + & + \\
\hline Age & SFBs participants age & + & + \\
\hline People & SFBs employees & + & - \\
\hline Education & SFBs participants level of Education & + & + \\
\hline Having/Using IT & SFBs using/having IT & + & + \\
\hline
\end{tabular}

Source: own compilation.

As shown in Table 3 most of the variables such as (having technology, telephone infrastructure, Internet infrastructure, gender, age, people) in the logistic regression model [Table: 2] are found to be positive and significant determinants in influencing the performance of SFBs. However, education of the SFBs owner/manager is found to be negative.

\section{Conclusion}

This research study has met the objective of identifying IT factors that influence the annual performance of small family businesses (SFBs) in the Lumbini zone Nepal. This research has identified the factors those are huddle for SFBs in terms of adopting IT. This may remove the gap between SFBs and government which is believed to be the principal cause of government failure in the management of SFBs and build a social awareness in order to help SFBs by increasing their annual turnover.

The Logistic regression technique was used to test the research hypotheses. The result of statistical analysis on the data revealed that out of the seven hypotheses developed; six hypothesis ( having technology, telephone infrastructure, Internet infrastructure, gender, age, people influence in SFBs annual turnover) found to be positive factors but one hypothesis 'education' was negative factor. It was also found that estimated probability that the turnover of SFBs increase with respect to age.

So, based on this study we can firm different policies are needed for SFBs to gear towards IT adoption and improve their annual performance. For an example; SFBs should be prioritized in programs promoting IT adoption by providing trainings; reading materials about information technologies. Districts related constraints also have to be considered as it was found not having telephone and internet can discourage SFBs owner/managers from adopting IT. Although all other factors are positive; if policy makers consider a need to sensitize SFBs to adopt IT providing education, improving infrastructure to increase IT adoption which would in turn positively influence the annual overhead of SFBs.

\section{Research Contributions}

Despite the large number of studies having addressed the concept of IT in SMEs (Small and Medium Enterprises'), limited research has focused on the impact of IT in a SFBs (Small Family Businesses). Moreover; to the best of the knowledge of the author, such research investigations have not touched the IT impact factors and their annual turnover performance.

Therefore; this research offers significant contributions to the existing body of knowledge in the research field of IT in small family business (SFBs), more specifically in IT impact in annual turnover performance. Such contribution is in the form of a theoretically based and empirically tested IT adoption, consisting of seven variables. Also, this study contributes in development of literature regarding the use of IT for the growth of SFBs.

\section{Limitations and Further Research}

Further studies and empirical research may be done in this area by using its recommendations in the future. Some of the research limitation and future research directions are listed below:

First: In this research study the geographical coverage of the sample is relatively small to represent whole country. A sample of SFBs were taken from the western part of Nepal. Further study may be done in order to yield more credible result to represent the country. For this purpose one may increase sample size and cover larger area not covered by this research. 
Second: This research study includes different important factors. But the cultural part was not tested as a factor. Further study may include the possible influence of cultural factors as there is an on-going debate about the differences in the use of IT across different countries because largely, IT adoption is related to many issues regarding security to regulatory issues to cultural beliefs about technology. This means that each country may have a slightly different point of view about specific technology adoption from their cultural perspective.

Finally, replication of this research on different industries may provide data for comparative study.

\section{References}

1. Aaker, D. A., Kumar, V., Day, G. S., and Marcondes, R. C. (2004). Pesquisa de marketing. Atlas.

2. Abouzeedan, A. and Busler, M. (2006). Information technology (it) and small and medium-sized enterprises (SMEs) management the concept of â firm impact spher .Global Business Review, 7(2), 243-257.

3. Adhikari, S. and Pradhan, D. B. (2002). Asian cases on supply chain management for SMEs. In Report of the Symposium on Supply Chain Management for Small and Medium Enterprises, Asian Productivity Organization, Taipei, Republic of China.

4. Alutto, J. and Hrebiniak, L. (1975). Research on commitment to employing organizations: Preliminary findings on a study of managers graduating from engineering and MBA programs. In Annual Meeting of the Academy of Management, New Orleans.

5. Anderson, J. E. and Schwager, P. H. (2004). SME adoption of wireless LAN technology: applying the utaut model. In Proceedings of The 7th Annual Conference Of The Southern Association For Information Systems, 7, 39-43.

6. Attewell, P. (1992). Technology diffusion and organizational learning: The case of business computing. Organization Science, 3(1), 1-19.

7. Baakeel, O. and Alrashidi, A. (2012). The impact of interest rate on profit among the United Arab Emirates UAE Small and Medium companies. European Journal of Business and Management, 4(5), 1-6.

8. Baard, V. C. (2003). The Design and Implementation of an Interactive IT Consulting System to Improve Performance in South African Small Business. PhD thesis.

9. Bajwa, W., Sayeed, A., and Nowak, R. (2005). Matched source-channel communication for field estimation in wireless sensor networks. In Proceedings of the 4th international symposium on Information processing in sensor networks, p. 44. IEEE Press.

10. Berry, R. and Wood, J. (1998). A survey of information technology use by small business.

11. Bhattarai, K. and Gupta, M. K. (2008). Implementation of e-government in Nepal: prospects, opportunities and threats. In Proceedings of the 2nd international conference on Theory and practice of electronic governance, pp. 483-484. ACM.

12. Brock, J. (2000). Information and communication technology in the small firm. Enterprise and Small Business, Harlow, Pearson Education, Financial Times, Prentice-Hall, Englewood Cliffs, NJ.

13. Brown, D. H. and Thompson, S. (2011). Priorities, policies and practice of e-government in a developing country context: ICT infrastructure and diffusion in Jamaica. European Journal of Information Systems, 20(3), 329-342.

14. Bruque, S. and Moyano, J. (2007). Organisational determinants of information technology adoption and implementation in SMEs: The case of family and cooperative firms. Technovation, 27(5), 241-253.

15. Bryman, A. (2008). Why do researchers integrate/combine/mesh/blend/mix/merge/fuse quantitative and qualitative research. Advances in mixed methods research, pp. 87-100.

16. Caldeira, M. M. and Ward, J. M. (2003). Using resource-based theory to interpret the successful adoption and use of information systems and technology in manufacturing small and medium-sized enterprises. European Journal of Information Systems, 12(2), 127-141.

17. Cao, X. and Mokhtarian, P. L. (2005). How do individuals adapt their personal travel? a conceptual exploration of the consideration of travel-related strategies. Transport Policy, 12(3), 199-206.

18. Carlsson, G. and Karlsson, K. (1970). Age, cohorts and the generation of generations. American Sociological Review, pp. 710-718.

19. Chang, M. K., Cheung, W., and Lai, V. S. (2005). Literature derived reference models for the adoption of online shopping. Information \& Management, 42(4), 543-559.

20. Child, J. (1974). Managerial and organizational factors associated with company performance part i. Journal of Management studies, 11(3), 175-189.

21. Choudrie, J. and Dwivedi, Y. K. (2005). Investigating the research approaches for examining technology adoption issues. Journal of Research Practice, 1(1), Article-D1. 
22. Chown, S. M. (1960). A factor analysis of the wesley rigidity inventory: its relationship to age and nonverbal intelligence. The Journal of Abnormal and Social Psychology, 61(3), 491.

23. Chuang, T.-T., Nakatani, K., and Chen, T. T. (2015). An exploratory study of expected business value of cloud computing. Issues in Information Systems, 16(4).

24. Cooper, D. R., Schindler, P. S., et al. (2003). Business research methods.

25. Creswell, J. W. (2013). Research design: Qualitative, quantitative, and mixed methods approaches. Sage.

26. Culkin, N. and Smith, D. (2000). An emotional business: a guide to understanding the motivations of small business decision takers. Qualitative Market Research: An International Journal, 3(3), 145-157.

27. Czaja, S. J. and Sharit, J. (1998). Age differences in attitudes toward computers. The Journals of Gerontology Series B: Psychological Sciences and Social Sciences, 53(5), 329-340.

28. Davis, P. S. and Harveston, P. D. (2000). Internationalization and organizational growth: The impact of internet usage and technology involvement among entrepreneur-led family businesses. Family Business Review, 13(2), 107-120.

29. Dosi, G. (1982). Technological paradigms and technological trajectories: a suggested interpretation of the determinants and directions of technical change. Research Policy, 11(3), 147-162.

30. Drew, S. (2003). Strategic uses of e-commerce by SMEs in the east of England. European Management Journal, 21(1), 79-88.

31. Dwivedi, Y. K., Papazafeiropoulo, A., Chuang, T.-T., Nakatani, K., and Zhou, D. (2009). An exploratory study of the extent of information technology adoption in SMEs: an application of upper echelon theory. Journal of Enterprise Information Management, 22(1/2), 183-196.

32. Evans, D. and Yen, D. C. (2005). E-government: An analysis for implementation: Framework for understanding cultural and social impact. Government Information Quarterly, 22(3), 354-373.

33. Fink, D. (1998). Guidelines for the successful adoption of information technology in small and medium enterprises. International journal of information management, 18(4), 243-253.

34. Gallo, M. A. and Pont, C. G. (1996). Important factors in family business internationalization. Family Business Review, 9(1), 45-59.

35. Gahtani, S. (2001). The applicability of tam outside North America: an empirical test in the United Kingdom. Information Resources Management Journal (IRMJ), 14(3), 37-46.

36. Gautam, P. (2012). Towards an Efficacious Adoption of IT in Developing Countries: A case of Nepal. LAP Lambert Academic Publishing.

37. Gefen, D. and Straub, D. W. (1997). Gender differences in the perception and use of e-mail: An extension to the technology acceptance model. MIS quarterly, pages 389-400.

38. Ghobakhloo, M., Arias-Aranda, D., and Benitez-Amado, J. (2011). Information technology implementation success within SMEs in developing countries: An interactive model. Information technology, 20:0018.

39. Gillard, H., Howcroft, D., Mitev, N., and Richardson, H. (2008). “missing women”: Gender, ICTs, and the shaping of the global economy. Information technology for development, 14(4), 262-279.

40. Hair, J. F. (2010). Multivariate data analysis.

41. Hallal, J. (2010). Electronic commerce within Australian small enterprises context: implications and outcomes. epubs.scu.edu.au.

42. Hambrick, D. C. and Mason, P. A. (1984). Upper echelons: The organization as a reflection of its top managers. Academy of Management Review, 9(2), 193-206.

43. Hardy, A. P. (1980). The role of the telephone in economic development. Telecommunications Policy, 4(4), 278-286.

44. Harrison, L. and Huntington, S. P. (2001). CulturaEs Lo QueImporta. Planeta.

45. Hartono, J. (2012). Adoption of information technology on small businesses: The role of environment, organizational and leader determinant.

46. Hasnu, S. and Amjad, S. (2007). Factors determining success of microenterprises: Evidence from district Peshawar. Gomal University Journal of Research, 23, 38-45.

47. Hausman, A. (2005). Innovativeness among small businesses: Theory and propositions for future research. Industrial Marketing Management, 34(8), 773-782.

48. Heilbrun, A. B. (1976). Measurement of masculine and feminine sex role identities as independent dimensions. Journal of Consulting and Clinical Psychology, 44(2), 183.

49. Hofstede, G. (1994). The business of international business is culture. International Business Review, 3(1), $1-14$.

50. Huber, F., Herrmann, A., and Morgan, R. E. (2001). Gaining competitive advantage through customer value oriented management. Journal of Consumer Marketing, 18(1), 41-53. 
51. Huy, L. V. and Filiatrault, P. (2006). The adoption of e-commerce in SMEs in Vietnam: a study of users and prospectors. PACIS 2006 Proceedings, p. 74.

52. Hymer, S. (1976). The international operations of national firms: A study of direct foreign investment, vol. 14. MIT press Cambridge, MA.

53. Iacobucci, D. and Churchill, G. (2010). Marketing research: methodological foundations (p. 257). Mason, $\mathrm{OH}$, USA: South-Western Cengage Learning.

54. Jamison, D. T., Lau, L. J., et al. (1982). Farmer education and farm efficiency. Johns Hopkins University Press.

55. Joseph, J. L. and Mukhopadhyay, S. (2010). A bi-national examination of gender and it adoption. International Journal of Society Systems Science, 2(3), 255-268.

56. Kandel, B. K. and Hota, J. (2012). Information technology adoption in small family businesses for developing economies. IUP Journal of Entrepreneurship Development, 9(1).

57. Kapurubandara, M. and Lawson, R. (2007). SMEs in developing countries need support to address the challenges of adopting e-commerce technologies.

58. Kasekende, L. A., Oshikoya, T. W., Ondiege, P. O., and Dasah, B. Z. (2007). Competitiveness and investment climate in sane economies. In The World Economic Forum's, The Africa Competitiveness Report.

59. Kirby, D. A. and Turner, M. J. (1993). It and the small retail business. International Journal of Retail \& Distribution Management, 21(7).

60. Knol, W. H. and Stroeken, J. (2001). The diffusion and adoption of information technology in small-and medium-sized enterprises through it scenarios. Technology Analysis \& Strategic Management, 13(2), 227-246.

61. Kraemer, K. L., Gibbs, J., and Dedrick, J. (2005). Impacts of globalization on e-commerce use and firm performance: A cross-country investigation. The Information Society, 21(5), 323-340.

62. Krejcie, R. V. and Morgan, D. W. (1970). Determining sample size for research activities. EducPsychol Meas.

63. Laforet, S. and Tann, J. (2006). Innovative characteristics of small manufacturing firms. Journal of Small Business and Enterprise Development, 13(3), 363-380.

64. Landauer, T. K. (1995). The trouble with computers: Usefulness, usability, and productivity, volume 21. Taylor \& Francis.

65. Lesjak, D., Lynn, M. L., and Bobek, S. (1998). Information technology in small Slovene firms: is strategic usage bypassed?

66. Levenburg, N. M. (2005). Does size matter? small firms' use of e-business tools in the supply chain. Electronic Markets, 15(2), 94-105.

67. Link, A. N. and Bozeman, B. (1991). Innovative behavior in small-sized firms. Small Business Economics, 3(3), 179-184.

68. Locke, T. (2004). Critical discourse analysis. Bloomsbury Publishing.

69. Looi, H. C. (2005). E-commerce adoption in bruneidarussalam: a quantitative analysis of factors influencing its adoption. Communications of the Association for Information Systems, 15(1), 3.

70. Lu, J., Plataniotis, K. N., and Venetsanopoulos, A. N. (2003). Regularized discriminant analysis for the small sample size problem in face recognition. Pattern Recognition Letters, 24(16), 3079-3087.

71. Lybaert, N. (1998). The information use in a sme: its importance and some elements of influence. Small Business Economics, 10(2), 171-191.

72. MacGregor, R. and Vrazalic, L. (2007). Small business clusters and their role in prioritising barriers to ecommerce adoption: a study of two approaches to cluster development. International Journal of Electronic Marketing and Retailing, 1(3), 236-259.

73. Martin, L. M. and Halstead, A. (2003). Knowledge and learning in female team-managed firms adopting information communication technologies (icts). Women in Management Review, 18(6), 334-337.

74. McCauley, L. A., Anger, W. K., Keifer, M., Langley, R., Robson, M. G., and Rohlman, D. (2006). Studying health outcomes in farmworker populations exposed to pesticides. Environmental Health Perspectives, pp. 953-960.

75. Mingers, J. (2001). Combining is research methods: towards a pluralist methodology. Information Systems Research, 12(3), 240-259.

76. Molla, A. and Licker, P. S. (2005). ecommerce adoption in developing countries: a model and instrument. Information \& Management, 42(6), 877-899.

77. Mukti, N. A. (2000). Barriers to putting businesses on the internet in malaysia. The Electronic Journal of Information Systems in Developing Countries, 2. 
78. Norton, S. W. (1992). Transaction costs, telecommunications, and the microeconomics of macroeconomic growth. Economic Development and Cultural Change, pp. 175-196.

79. Ochara, N. M., Van Belle, J.-P., and Brown, I. (2008). Global diffusion of the internet xiii: Internet diffusion in kenya and its determinants - a longitudinal analysis. Communications of the Association for Information Systems, 23(1), 7.

80. Ogbonna, E. and Harris, L. C. (2005). The adoption and use of information technology: A longitudinal study of a mature family firm. New Technology, Work and Employment, 20(1), 2-18.

81. Oviatt, B. M., McDougall, P. P., and Loper, M. (1995). Global start-ups: Entrepreneurs on a worldwide stage [and executive commentary]. The Academy of Management Executive (1993-2005), pp. 30-44.

82. Palvia, P. C. and Palvia, S. C. (1999). An examination of the it satisfaction of small-business users. Information \& Management, 35(3), 127-137.

83. Pant, P. (2009). Social science research and thesis writing. Buddha Academic Enterprises Pvt. Ltd.

84. Premkumar, G. (2003). A meta-analysis of research on information technology implementation in small business. Journal of Organizational Computing and Electronic Commerce, 13(2), 91-121.

85. Qureshi, S. and Hoppel, C. (1995). Profiling computer predispositions. Journal of Professional Services Marketing, 12(1), 73-83.

86. Rogers Everett, M. (1995). Diffusion of innovations. New York.

87. Roscoe, J. T. (1975). Fundamental research statistics for the behavioral sciences [by] John T. Roscoe. Holt, Rinehart and Winston, New York, NY.

88. Salampasis, M., Bicoku, Y., Androulidakis, S., Samathrakis, V., and Batzios, C. (2001). Adoption of it for extension services in developing countries: Practice and experience from the Albanian case. In Third European Conference of the European Federation for Information Technology in Agriculture, Proceedings, vol. 2, pp. 663-668.

89. Sekaran, U. (2000). Research methods for business: A skill-building approach. USA: John willey\& sons.

90. Stedham, Y. E. and Yamamura, J. H. (2004). Measuring national culture: does gender matter? Women in Management Review, 19(5), 233-243.

91. Tan, Y. L. and Macaulay, L. A. (2007). Adoption of ICT among small business: vision vs. reality. International Journal of Electronic Business, 5(2), 188-203.

92. Teo, T. S., Srivastava, S. C., and Jiang, L. (2008). Trust and electronic government success: An empirical study. Journal of Management Information Systems, 25(3), 99-132.

93. Thapa, B. B. and Paudel, M. S. (2006). Subject policies and programs of SMEs in Nepal.

94. Thong, J. Y. (1999). An integrated model of information systems adoption in small businesses. Journal of Management Information Systems, 15(4), 187-214.

95. Thong, J. Y. (2001). Resource constraints and information systems implementation in Singaporean small businesses. Omega, 29(2), 143-156.

96. Thong, J. Y. and Yap, C.-S. (1995). Ceo characteristics, organizational characteristics and information technology adoption in small businesses. Omega, 23(4), 429-442.

97. Thong, J. Y., Yap, C.-S., and Raman, K. (1996). Top management support, external expertise and information systems implementation in small businesses. Information Systems Research, 7(2), 248-267.

98. Venkatesh, V. and Davis, F. D. (2000). A theoretical extension of the technology acceptance model: four longitudinal field studies. Management Science, 46(2), 186-204.

99. Welsh, J. A. and White, J. F. (1981). Converging on characteristics of entrepreneurs. Frontiers of Entrepreneurship Research, pp. 504-515.

100. Zwicker, R., de Souza, C. A., and da Rocha Vidal, A. G. (2006). An assessment on the Informatization of Brazilian industrial companies. The Electronic Journal of Information Systems in Developing Countries, 23. 